\title{
Functional mitral stenosis after surgical annuloplasty for ischemic mitral regurgitation: Importance of subvalvular tethering in the mechanism and dynamic deterioration during exertion
}

\author{
Kayoko Kubota, MD, ${ }^{\mathrm{a}}$ Yutaka Otsuji, MD, ${ }^{\mathrm{d}}$ Tetsuya Ueno, MD, ${ }^{\mathrm{b}}$ Chihaya Koriyama, MD, ${ }^{\mathrm{c}}$ \\ Robert A. Levine, MD, ${ }^{\mathrm{e}}$ Ryuzo Sakata, MD, ${ }^{\mathrm{b}}$ and Chuwa Tei, $\mathrm{MD}^{\mathrm{a}}$
}

\begin{abstract}
Objective: Diastolic subvalvular mitral leaflet tethering by left ventricular remodeling that restricts leaflet opening in the presence of annular size reduction by surgery for ischemic mitral regurgitation potentially causes functional mitral stenosis in the absence of organic leaflet lesions. Exercise, known to worsen systolic tethering and ischemic mitral regurgitation, might also dynamically exacerbate such mitral stenosis by increasing tethering. This study evaluates the mechanism and response of such mitral stenosis to exercise.
\end{abstract}

Methods: We measured the diastolic mitral valve area, annular area, and peak and mean transmitral pressure gradient by echocardiography in 20 healthy individuals and 31 patients who underwent surgical annuloplasty for ischemic mitral regurgitation.

Results: Although the mitral valve area and annular area did not significantly differ in healthy individuals $(4.7 \pm$ $0.6 \mathrm{~cm}^{2}$ vs $5.2 \pm 0.6 \mathrm{~cm}^{2}$, not significant), mitral valve area was significantly smaller than the annular area in patients after annuloplasty $\left(1.6 \pm 0.2 \mathrm{~cm}^{2}\right.$ vs $\left.3.3 \pm 0.5 \mathrm{~cm}^{2}, P<.01\right)$. The mitral valve area was less than $1.5 \mathrm{~cm}^{2}$ only after the surgery $(P<.01)$ and was significantly correlated with restricted leaflet opening $\left(\mathrm{r}^{2}=\right.$ $0.74, P<.001)$, left ventricular dilatation $\left(\mathrm{r}^{2}=0.17, P<.05\right)$, and New York Heart Association functional class $(P<.05)$. Exercise stress echocardiography of 12 patients demonstrated dynamic worsening in functional mitral stenosis (mitral valve area: $2.0 \pm 0.5 \mathrm{~cm}^{2}$ to $1.4 \pm 0.2 \mathrm{~cm}^{2}, P<.01$; mean pressure gradient: $1.5 \pm 0.9 \mathrm{~mm} \mathrm{Hg}$ to $6.0 \pm 2.2 \mathrm{~mm} \mathrm{Hg}, P<.01)$.

Conclusions: Persistent subvalvular leaflet tethering in the presence of annular size reduction by surgery in ischemic mitral regurgitation frequently causes functional mitral stenosis at the leaflet tip level, which is related to heart failure symptoms and can be dynamic with significant exercise-induced worsening. (J Thorac Cardiovasc Surg 2010;140:617-23)

The basic mechanism of ischemic mitral regurgitation (MR) is leaflet tethering by outward displacement of the papillary muscles (PMs) as the result of left ventricular (LV) remodeling. ${ }^{1-6}$ Therefore, systolic leaflet closure is restricted in these patients. Reduced diastolic leaflet opening in patients with LV dysfunction has also been observed and was long interpreted as reflecting a reduction in mitral inflow volume. ${ }^{7}$ However, mitral leaflet opening is inde-

\footnotetext{
From the Departments of Cardiovascular Medicine, ${ }^{\mathrm{a}}$ Cardiovascular Surgery, ${ }^{\mathrm{b}}$ and Public Health, ${ }^{c}$ Graduate School of Medicine, Kagoshima University, Kagoshima, Japan; Second Department of Internal Medicine, University of Occupational and Environmental Health, ${ }^{\mathrm{d}}$ Kitakyushu, Japan; and Massachusetts General Hospital, ${ }^{\mathrm{e}}$ Boston, Massachusetts.

Dr Otsuji was supported by Grants-in-Aid for Scientific Research 19500431 and 21500458 from the Japan Society for the Promotion of Science, Tokyo, Japan.

Disclosures: None.

Received for publication March 12, 2009; revisions received Sept 15, 2009; accepted for publication Nov 2, 2009; available ahead of print Feb 1, 2010.

Address for reprints: Yutaka Otsuji, MD, Second Department of Internal Medicine, School of Medicine, University of Occupational and Environmental Health, Iseigaoka 1-1, Yahatanishi-ku, Kitakyushu 807-8555, Japan (E-mail: otsujiy@med. uoeh-u.ac.jp).

$0022-5223 / \$ 36.00$

Copyright (c) 2010 by The American Association for Thoracic Surgery

doi:10.1016/j.jtcvs.2009.11.003
}

pendent of inflow volume, ${ }^{8,9}$ and reduced leaflet opening in LV dysfunction is now understood as reflecting a restriction in diastolic leaflet mobility by subvalvular tethering (Figure 1, A, middle). ${ }^{9,10}$ Diastolic leaflet tethering alone in patients with systolic LV dysfunction is not usually critical enough to cause significant mitral stenosis (MS). ${ }^{9}$ However, high incidence of functional MS with a mitral valve area (MVA) less than $1.5 \mathrm{~cm}^{2}$ has recently been reported in patients who underwent surgical mitral annuloplasty for ischemic MR. ${ }^{11}$ The next question is why such patients frequently have MVA less than $1.5 \mathrm{~cm}^{2}$ despite the fact that the implanted ring area is $2.7 \mathrm{~cm}^{2}$ even at its smallest size (Carpentier-Edwards Physio ring 24; Edwards Lifesciences, Irvine, Calif). After annular size reduction by surgery, restricted diastolic leaflet mobility by subvalvular tethering might further limit valve opening, which could lead to significant MS even in the absence of organic leaflet lesions (functional MS) (Figure 1, A, right). Mitral leaflet opening in patients after surgical ring annuloplasty for ischemic MR has yet to be fully investigated.

We hypothesized that surgical annuloplasty for ischemic MR that reduces annular size can occasionally result in 


$$
\begin{aligned}
& \text { Abbreviations and Acronyms } \\
& \text { EDV }=\text { end-diastolic volume } \\
& \text { ESV }=\text { end-systolic volume } \\
& \text { LV } \quad \text { left ventricular } \\
& \text { MR }=\text { mitral regurgitation } \\
& \text { MS }=\text { mitral stenosis } \\
& \text { MVA }=\text { mitral valve area } \\
& \text { NYHA }=\text { New York Heart Association } \\
& \text { PG }=\text { pressure gradient } \\
& \text { PM }=\text { papillary muscle }
\end{aligned}
$$

significant functional MS, which is related to subvalvular tethering. We further hypothesized that such functional MS with diastolic subvalvular tethering can therefore be dynamic and may worsen during exercise, which is known to worsen systolic MR because of subvalvular tethering dynamically as well. ${ }^{12,13}$ Therefore, the present study evaluated diastolic MVA and the transmitral pressure gradient (PG), as well as the effects of exercise on both MVA and PG in patients who have undergone surgical annuloplasty for ischemic MR.

\section{MATERIALS AND METHODS Patients}

We evaluated 60 consecutive patients who underwent serial echocardiography before and after surgical annuloplasty for ischemic MR and coronary artery bypass grafting between May 2000 and July 2005 at Kagoshima University Hospital. Ischemic MR was diagnosed by echocardiography and coronary angiography findings using the following criteria: (1) presence of MR, (2) absence of organic mitral leaflet lesions, (3) apically displaced leaflet coaptation, ${ }^{1-4}$ and (4) presence of ischemic heart disease with LV dysfunction. Annuloplasty was performed for patients with MR more than mild and for those with mild MR at preoperative evaluation but with a history of heart failure or MR more than mild. Inclusion criteria were the performance of (1) surgical annuloplasty for ischemic MR and (2) serial echocardiography before and after the procedure. Exclusion criteria were (1) atrial fibrillation, excluded because of potential difficulty in measuring MVA by the continuity equation, which was required for this study; and (2) concomitant subvalvular surgical procedures to address tethering, such as LV plasty, PM approximation, and chordal cutting, excluded because of their potential beneficial effects on leaflet opening to reduce postoperative functional MS. ${ }^{14}$ Two patients were excluded because of atrial fibrillation, 21 patients were excluded because of concomitant subvalvular procedures, and 6 patients were excluded because of both atrial fibrillation and subvalvular procedures. No patient was excluded for other reasons. It is our policy to perform subvalvular procedures, rather than to reduce annular size aggressively, to address tethering in patients with severe ischemic MR, chronic heart failure, or advanced LV remodeling. In this way, 31 consecutive patients with coronary artery bypass grafting and isolated annuloplasty without downsizing for mild to moderate/severe ischemic MR were enrolled
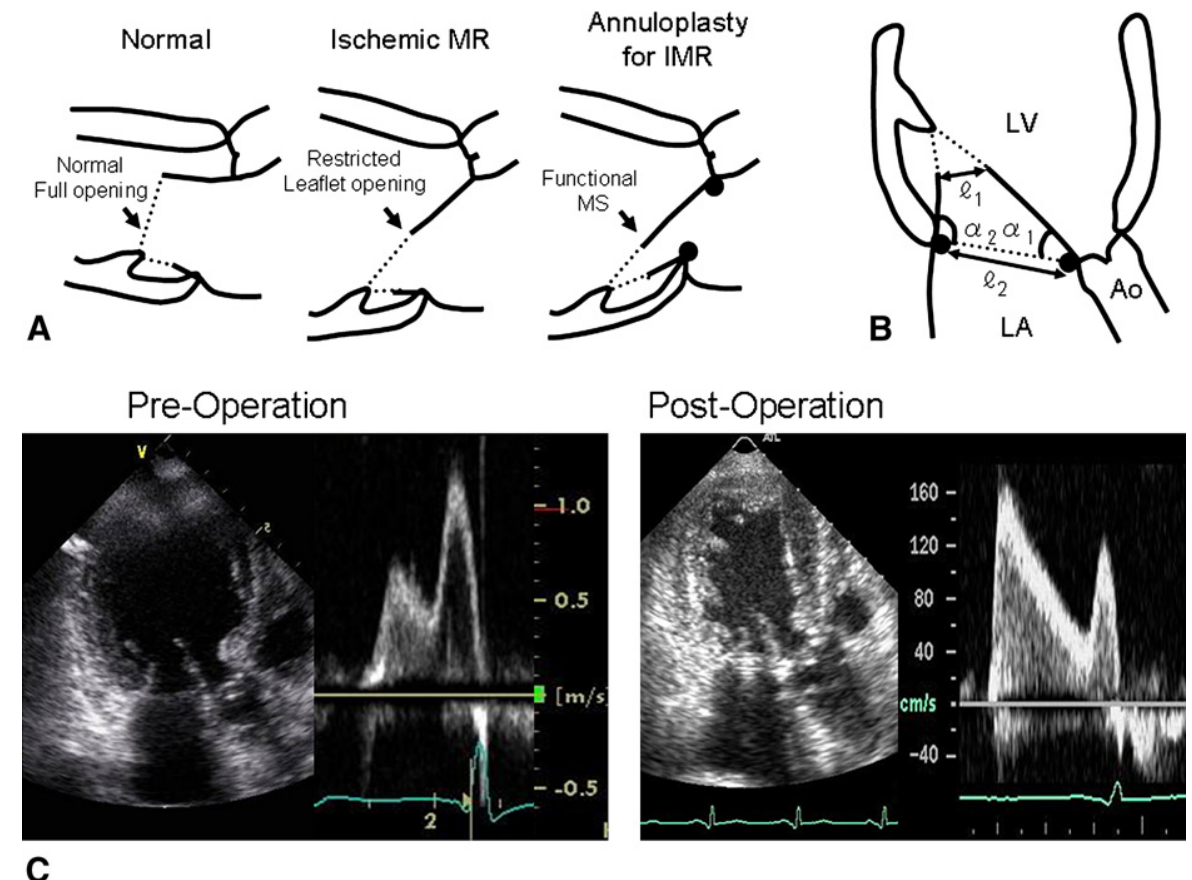

FIGURE 1. A, Potential mechanism of functional MS after surgical annuloplasty for ischemic MR. Valve tethering in ischemic MR restricts leaflet mobility even in diastole, thereby reducing leaflet opening (middle). However, MVA is not usually small enough to cause significant MS. Surgical annuloplasty to reduce annular size might further limit valve opening, which could result in significant functional MS without organic leaflet disease (right). B, Methods to quantify diastolic mitral leaflet tethering in apical long-axis view. $\alpha 1$ and $\alpha 2$ express diastolic tethering of anterior and posterior leaflets, respectively. Mitral

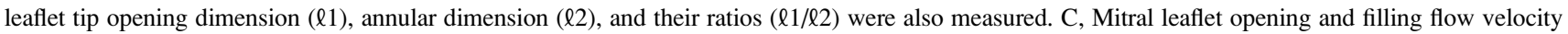
before and after surgical annuloplasty for ischemic MR. Before surgery, leaflet opening angle $\alpha 1$ is restricted, leaflet opening dimension is mildly reduced, and filling flow velocity is mildly increased. After surgery, leaflet opening dimension is further reduced and increase in filling flow velocity is significant. Ao, Aorta, $L A$, left atrium; $L V$, left ventricle; $M S$, mitral stenosis; $M R$, mitral regurgitation; $I M R$, ischemic mitral regurgitation. 
in this study. The control group included 20 individuals who underwent echocardiography and had no evidence of cardiovascular disease. Table 1 summarizes the patients' profiles.

\section{Surgical Technique}

The mitral valve was intraoperatively evaluated using a standard left atriotomy. Mitral annuloplasty with a Carpentier-Edwards Physio ring was performed when preoperative echocardiography indicated MR more than mild. A Carpentier-Edwards Physio ring or a partial flexible linear reducer (a stainless-steel wire sealed within a polyester sheath; Gamida Medical and Surgical Equipment, Eaubonne Cedex, France) was used when the MR was mild. Ring size was selected by intertrigonal length without downsizing. All patients were managed after surgery with standard medications, and intraoperative transesophageal echocardiography confirmed the absence of MR. The ethics committee of Kagoshima University approved the study protocol, and written informed consent was obtained from all patients to participate in the study.

\section{Echocardiography}

All patients were examined by standard 2-dimensional and Doppler echocardiography 1 week before and 2 weeks to 2 years after the surgery.

TABLE 1. Patients' profiles

\begin{tabular}{|c|c|c|}
\hline & $\begin{array}{c}\text { Control } \\
(\mathbf{N}=\mathbf{2 0})\end{array}$ & $\begin{array}{c}\text { Annuloplasty for } \\
\text { ischemic MR } \\
(\mathbf{N}=\mathbf{3 1}) \\
\end{array}$ \\
\hline Age (y) & $41-84(59 \pm 12)$ & $41-82(66 \pm 11)$ \\
\hline Male/female & $13 / 7$ & $23 / 8$ \\
\hline \multicolumn{3}{|l|}{ NYHA class } \\
\hline (1 wk before surgery) & N/A & $2-4(2.5 \pm 0.5)$ \\
\hline (at maximal symptom) & N/A & $2-4(3.4 \pm 0.6)$ \\
\hline $\begin{array}{l}\text { Preoperative angina } \\
\text { pectoris }\end{array}$ & $0 / 20$ & $22 / 31$ \\
\hline \multicolumn{3}{|l|}{ Coronary risk factors } \\
\hline Hyperlipidemia & $2 / 20$ & $15 / 31$ \\
\hline DM & $0 / 20$ & $10 / 31$ \\
\hline Hypertension & $3 / 20$ & $18 / 31$ \\
\hline Smoking & $4 / 20$ & $19 / 31$ \\
\hline \multicolumn{3}{|l|}{ Site of MI } \\
\hline Anterior & $0 / 20$ & $10 / 31$ \\
\hline Inferoposterior & $0 / 20$ & $8 / 31$ \\
\hline Anterior + inferoposterior & $0 / 20$ & $13 / 31$ \\
\hline $\begin{array}{l}\text { MR severity } \\
\text { (1 wk before surgery) }\end{array}$ & N/A & \\
\hline Mild & & $17 / 31$ \\
\hline Moderate & & $12 / 31$ \\
\hline Severe & & $2 / 31$ \\
\hline \multicolumn{3}{|l|}{$\begin{array}{l}\text { MR severity } \\
\text { (at maximal symptom) }\end{array}$} \\
\hline Mild & & $0 / 31$ \\
\hline Moderate & & $13 / 31$ \\
\hline Severe & & $16 / 31$ \\
\hline No. of CABG & & $1-6(3.7 \pm 1.2)$ \\
\hline MV annuloplasty & $0 / 20$ & $31 / 31$ \\
\hline Carpentier-Edwards ring* & $0 / 20$ & $22 / 31$ \\
\hline Size $(\mathrm{mm})$ & N/A & $26-32(28 \pm 2.0)$ \\
\hline Linear reducer & $0 / 20$ & $9 / 31$ \\
\hline
\end{tabular}

$M R$, Mitral regurgitation; NYHA, New York Heart Association; N/A, not applicable; $D M$, diabetes mellitus; $L V$, left ventricle; $M I$, myocardial infarction; $C A B G$, coronary artery bypass grafting; $M V$, mitral valve. *Edwards Lifesciences, Irvine, Calif.
We determined LV end-diastolic volume (EDV), end-systolic volume (ESV), and ejection fraction using the Simpson's biplane method. The LV short- to long-axis dimension ratios in the end-systolic apical 4-chamber view were defined as LV sphericity. Diameters of the mitral annulus were measured from the orthogonal apical 4 and 2 chamber views to calculate annular area with an elliptical assumption. ${ }^{15}$ In the parasternal or apical longaxis view, MR was quantified by the narrowest jet origin, constituting the vena contracta width. ${ }^{16}$

\section{Measurement of Mitral Valve Opening Profile}

Transmitral filling flow velocity was recorded by pulsed Doppler echocardiography with the sample volume at the leaflet tip. Peak and mean transmitral PG were evaluated as follows: $\mathrm{PG}(\mathrm{mm} \mathrm{Hg})=4 \times$ velocity $^{2}(\mathrm{~m} / \mathrm{s})$. Because the mitral leaflet orifice was usually directed toward the PMs as opposed to the apex in the patients (Figure 1, A), MVA measurements in the conventional short-axis view frequently only allowed for an oblique crosssectional plane of the orifice, causing difficulties with measurements. Therefore, the diastolic MVA was obtained by the continuity equation (MVA $\times$ velocity time integral of mitral filling flow $=\mathrm{LV}$ filling volume $=\mathrm{LV}$ EDV - LV ESV) ${ }^{17}$ Diastolic mitral leaflet opening angles were quantified in the apical long-axis view (Figure 1,B), in which $\alpha 1$ and $\alpha 2$ were the anterior or posterior leaflet opening angles, respectively. Both the diastolic mitral leaflet tip opening distance and the annular dimension were also measured.

\section{Dynamic Evaluation of the Mitral Valve Opening During Exercise Stress Echocardiography}

Exercise stress echocardiography using upright ergometry was performed in 12 patients who provided written, informed consent to these procedures and who could undergo an echocardiographic study during the chronic phase after surgery. After an initial workload of $10 \mathrm{~W}$ for 2 minutes, the workload was increased by $5 \mathrm{~W}$ every 2 minutes. Exercise stress was stopped when patients developed dyspnea or leg fatigue. Peak and mean PG, as well as MVA, were measured both at the baseline and during maximal exercise.

\section{Statistical Analysis}

Results are expressed as mean \pm standard deviation. Differences between stages were explored using a paired $t$ test. Differences in incidence were evaluated using the chi-square test. Determinants were explored using a stepwise regression analysis. The relationship between New York Heart Association (NYHA) class and LV or mitral valve function was investigated using logistic regression analysis.

\section{RESULTS \\ Limited Mitral Valve Opening in Preoperative Patients With Ischemic Mitral Regurgitation}

Although the MVA and the annular area did not significantly differ in healthy individuals, the MVA was significantly smaller than the annular area in preoperative patients with ischemic MR and LV dysfunction $(P<.01)$ (Table 2). The reduction in the MVA was associated with significantly reduced leaflet opening angles and a reduced leaflet tip opening dimension $(P<.01$, for both). However, the reduction in the MVA and the associated transmitral PG were modest.

\section{Further Limitations in Mitral Valve Opening After Surgical Annuloplasty}

The mitral annulus was significantly smaller $(P<.01)$ and anterior leaflet opening was persistently restricted after the surgical procedure. However, the posterior leaflet opening 
TABLE 2. Limited mitral valve opening in patients with ischemic mitral regurgitation

\begin{tabular}{|c|c|c|c|}
\hline & \multirow[b]{2}{*}{$\begin{array}{l}\text { Control } \\
\mathbf{N}=\mathbf{2 0}\end{array}$} & \multicolumn{2}{|c|}{ Ischemic MR } \\
\hline & & $\begin{array}{c}\text { Presurgery } \\
\mathbf{N}=\mathbf{3 1}\end{array}$ & $\begin{array}{c}\text { Postsurgery } \\
\mathbf{N}=\mathbf{3 1}\end{array}$ \\
\hline LV EDV (mL) & $89 \pm 20$ & $153 \pm 46^{*}$ & $137 \pm 40^{*}$ \\
\hline LV ESV (mL) & $28 \pm 11$ & $92 \pm 40^{*}$ & $83 \pm 40^{*}$ \\
\hline $\mathrm{EF}(\%)$ & $70 \pm 8$ & $41 \pm 9 *$ & $42 \pm 13^{*}$ \\
\hline LV sphericity & $0.54 \pm 0.02$ & $0.66 \pm 0.07 *$ & $0.68 \pm 0.06^{*}$ \\
\hline MAA $\left(\mathrm{cm}^{2}\right)$ & $5.2 \pm 0.6$ & $6.9 \pm 0.9^{*}$ & $3.3 \pm 0.5^{*} \dagger$ \\
\hline \multicolumn{4}{|l|}{$\begin{array}{l}\text { Diastolic mitral } \\
\text { leaflet opening angle } \\
\text { (degree) }\end{array}$} \\
\hline$\alpha 1$ & $80 \pm 5$ & $68 \pm 7 *$ & $62 \pm 9^{*} \dagger$ \\
\hline$\alpha 2$ & $95 \pm 7$ & $78 \pm 9^{*}$ & $90 \pm 15^{*, \dagger}$ \\
\hline$\ell 1(\mathrm{~cm})$ & $2.2 \pm 0.3$ & $1.5 \pm 0.2^{*}$ & $1.0 \pm 0.3^{*} \uparrow$ \\
\hline$\ell 2(\mathrm{~cm})$ & $2.4 \pm 0.3$ & $3.3 \pm 0.5^{*}$ & $2.0 \pm 0.3^{*} \uparrow$ \\
\hline$\ell 1 / \ell 2$ & $0.89 \pm 0.10$ & $0.44 \pm 0.10^{*}$ & $0.5 \pm 0.10^{*} \dagger$ \\
\hline $\operatorname{MVA}\left(\mathrm{cm}^{2}\right)$ & $4.7 \pm 0.6$ & $3.5 \pm 0.7^{*}$ & $1.6 \pm 0.2^{*}, \dagger$ \\
\hline MVA $<1.5 \mathrm{~cm}^{2}$ & $0 / 20$ & $0 / 31$ & $13 / 31 * \dagger$ \\
\hline Peak PG (mm Hg) & $1.7 \pm 0.6$ & $3.5 \pm 2.6$ & $10.6 \pm 6.2^{*, \dagger}$ \\
\hline Mean PG (mm Hg) & $0.6 \pm 0.2$ & $0.8 \pm 0.8$ & $3.5 \pm 2.7^{*, \dagger}$ \\
\hline MR VC dimension (mm) & $0 \pm 0$ & $5.6 \pm 1.7$ & $1.9 \pm 1.6$ \\
\hline $\mathrm{MR} \mathrm{VC} \geq 5 \mathrm{~mm}$ & $0 / 20$ & $14 / 31$ & $1 / 31$ \\
\hline
\end{tabular}

angle $\alpha 2$ was significantly increased $(P<.01)$, suggesting that outward displacement of the PMs may not strongly limit posterior leaflet opening. After surgery, the leaflet tip opening dimension was further reduced, the MVA significantly decreased $(P<.01)$ to a mean value of $1.6 \pm 0.2 \mathrm{~cm}^{2}$, and the incidence of significant MS with MVA less than 1.5 $\mathrm{cm}^{2}$ was increased $(0 / 31$ to $13 / 31, P<.01)$. The peak and mean transmitral PG also significantly increased after surgery to $10.6 \pm 6.2 \mathrm{~mm} \mathrm{Hg}$ and $3.5 \pm 2.7 \mathrm{~mm} \mathrm{Hg}$, respectively $(P<.01)$ (Table 2$)$. Figure $1, C$ shows an example of functional MS with limited leaflet tip opening narrowing mitral inflow.

\section{Determinants of Diastolic Mitral Valve Area After Surgical Annuloplasty for Ischemic Mitral Regurgitation}

The MVA was less than $1.5 \mathrm{~cm}^{2}$ only after surgery $(P<.01)$. Multiple regression analysis identified independent contributions from the decreased leaflet tip opening dimension for the MVA $\left(\mathrm{r}^{2}=0.74, P<.001\right)$. Further multiple regression analyses identified independent contributions from the reduced anterior leaflet opening angle $\alpha 1$ for both the reduction in the leaflet tip opening dimension $\ell 1$ and its ratio to annular size $\left(r^{2}=0.25\right.$ and 0.24 , $P<.005$ and 0.05 , respectively). $\alpha 1$ was independently determined by the $\mathrm{LV}$ sphericity $\left(\mathrm{r}^{2}=0.38, P<.005\right)$. These results suggest that the postsurgical development of MS results from restricted anterior leaflet opening because of subvalvular tethering in the presence of surgical annular size reduction. Of note, there were no significant relationships between MVA and mitral inflow volume (LV EDV - LV ESV) preoperatively or postoperatively.

\section{Relationship Between Postoperative New York Heart Association Class and Left Ventricular or Mitral Valve Function}

Postoperative NYHA class was II in 16 patients and III in 15 patients. Univariate logistic regression analyses identified LV EDV, ESV, ejection fraction, sphericity index, MVA, and MR severity (vena contracta dimension) as significant determinants of NYHA class III $(P<.05)$. Multivariate logistic regression analysis identified both increased LV shortto long-axis dimension ratio greater than 0.68 (odds ratio, 11.1; 95\% confidence interval, 2.5-48.9) and MVA less than $1.5 \mathrm{~cm}^{2}$ (odds ratio, 19.2; $95 \%$ confidence interval, 3.66-101) as independent determinants of NYHA functional class $(P<.05)$.

\section{Dynamic Changes in Limited Mitral Valve Opening During Exercise}

Twelve patients were examined by exercise stress echocardiography. No complications developed, and peak exercise loads ranged from 20 to $55(33 \pm 12) \mathrm{W}$. The exercise stress was stopped because of dyspnea in 3 patients and leg fatigue in 9 patients. Table 3 summarizes the hemodynamic and echocardiographic data. Heart rate and systolic blood pressure significantly increased $(P<.05)$. The LV $\mathrm{EDV}, \mathrm{ESV}$, and sphericity tended to increase but without statistical significance. The mitral annular size remained constant, whereas anterior leaflet opening angle $\alpha 1$ and leaflet tip opening dimension were further and significantly reduced during exercise $(P<.01)$. Consequently, the MVA became significantly reduced $(P<.01)$ and both the peak and mean transmitral PG were significantly increased by exercise $(P<.01)$. Figure 2 shows a patient before and during exercise. Exercise tended to dilate the LV, reduce the mitral leaflet opening, and increase filling flow velocity. The MVA decreased from 1.9 to $1.3 \mathrm{~cm}^{2}$ in this patient.

\section{DISCUSSION}

\section{Functional Mitral Stenosis After Surgical}

Annuloplasty for Ischemic Mitral Regurgitation

The current study showed that mitral leaflet opening was frequently reduced after surgical annuloplasty for ischemic MR. Although the MVA was frequently less than $1.5 \mathrm{~cm}^{2}$, it was not associated with intrinsic leaflet disease. "Functional MS" seems to be an appropriate term to express this limitation of the area available for mitral inflow without intrinsic leaflet structural abnormalities, but due to abnormal 
TABLE 3. Dynamic changes in the limited mitral valve opening during exercise in patients with surgical annuloplasty for ischemic mitral regurgitation

\begin{tabular}{lccr}
\hline & Preexercise & During exercise & $\boldsymbol{P}$ value \\
\hline $\begin{array}{l}\text { Peak exercise } \\
\quad \text { load }(\mathrm{W})\end{array}$ & N/A & $33 \pm 12$ & N/A \\
HR (beats/min) & $68 \pm 10$ & $107 \pm 11$ & $<.01$ \\
Systolic BP (mm Hg) & $120 \pm 15$ & $158 \pm 20$ & $<.01$ \\
Diastolic BP (mm Hg) & $61 \pm 6$ & $67 \pm 9$ & .07 \\
LV EDV (mL) & $118 \pm 44$ & $136 \pm 51$ & .37 \\
LV ESV (mL) & $68 \pm 39$ & $83 \pm 46$ & .37 \\
LV sphericity & $0.7 \pm 0.1$ & $0.74 \pm 0.09$ & .43 \\
MAA $\left(\mathrm{cm}^{2}\right)$ & $3.6 \pm 0.4$ & $3.6 \pm 0.4$ & .87 \\
Diastolic mitral leaflet opening angle (degree) & & \\
$\alpha 1$ & $57 \pm 6$ & $46 \pm 8$ & $<.01$ \\
$\alpha 2$ & $99 \pm 17$ & $112 \pm 17$ & .09 \\
$\ell 1(\mathrm{~cm})$ & $1.0 \pm 0.1$ & $0.8 \pm 0.1$ & $<.05$ \\
$\ell 2\left(\mathrm{~cm}^{2}\right)$ & $2.0 \pm 0.2$ & $2.1 \pm 0.2$ & .92 \\
$\ell 1 / \ell 2$ & $0.5 \pm 0.02$ & $0.4 \pm 0.02$ & $<.01$ \\
MVA $\left(\mathrm{cm}^{2}\right)$ & $2.0 \pm 0.5$ & $1.4 \pm 0.2$ & $<.01$ \\
MVA $<1.5 \mathrm{~cm}^{2}$ & $2 / 12$ & $9 / 12$ & $<.01$ \\
Peak PG $(\mathrm{mm} \mathrm{Hg})$ & $5.7 \pm 3.0$ & $18.5 \pm 6.2$ & $<.01$ \\
Mean PG $(\mathrm{mm} \mathrm{Hg})$ & $1.5 \pm 0.9$ & $6.0 \pm 2.2$ & $<.01$ \\
\hline
\end{tabular}

$H R$, Heart rate; $N / A$, not applicable; $B P$, blood pressure; $L V$, left ventricle; $E D V$, enddiastole volume; $E S V$, end-systolic volume; $M A A$, mitral annular area; $M V A$, mitral valve area; $P G$, pressure gradient. leaflet opening function in the context of abnormal LV remodeling and surgical annular size reduction.

Reduced MVA was primarily related to restricted leaflet opening, which was independently related to LV dilatation. Significant MS only developed after annuloplasty. Further, the ratio of MVA to anterior leaflet opening (MVA/ $\alpha 1)$ significantly decreased after annuloplasty $\left(0.048 \pm 0.010 \mathrm{~cm}^{2} /\right.$ degree to $0.027 \pm 0.004 \mathrm{~cm}^{2} /$ degree, $P<.01$ ). Therefore, the likely cause of this MS was diastolic subvalvular leaflet tethering by $\mathrm{LV}$ remodeling in the presence of surgical reduction in annular size. Of note is that functional MS developed at the leaflet tip level with subvalvular tethering, as opposed to the annular level directly intervened. Statistical analysis indicated that the degree of the functional MS, recurrent MR, and LV function were all significantly related to NYHA functional class. In addition, the degree of the functional MS was significantly related to that of the recurrent MR (ie, the greater the MS, the greater the MR, $r^{2}=0.24$, $P<.01)$. These findings reveal that postoperative subvalvular tethering impairs not only leaflet closure ${ }^{18}$ but also leaflet opening, and thus contributes to the development of heart failure.

Finally, this MS was clinically relevant, especially with the exercise-induced dynamic worsening, which is consistent with the dynamic nature of systolic ischemic MR. ${ }^{12,13}$ In patients with rheumatic MS, increases in heart rate and
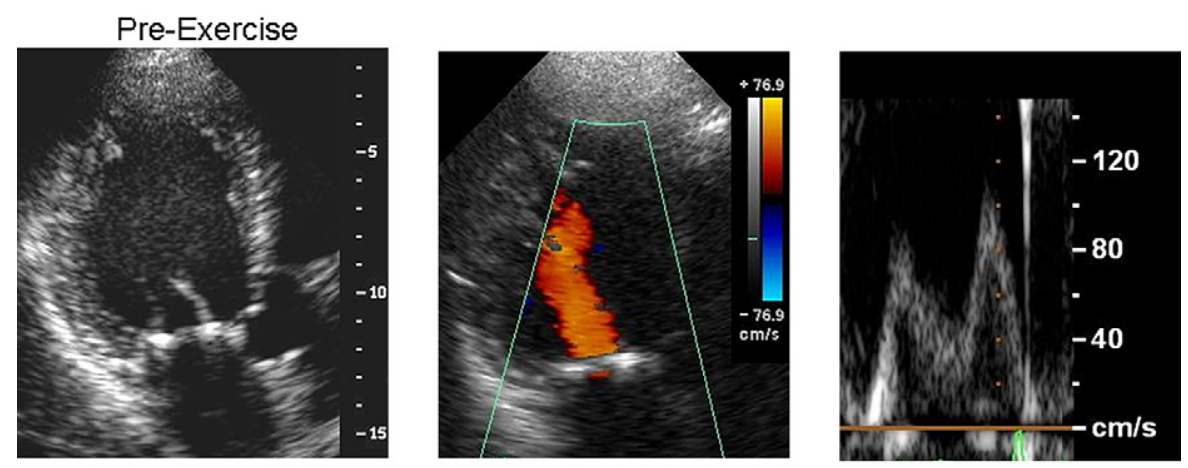

A
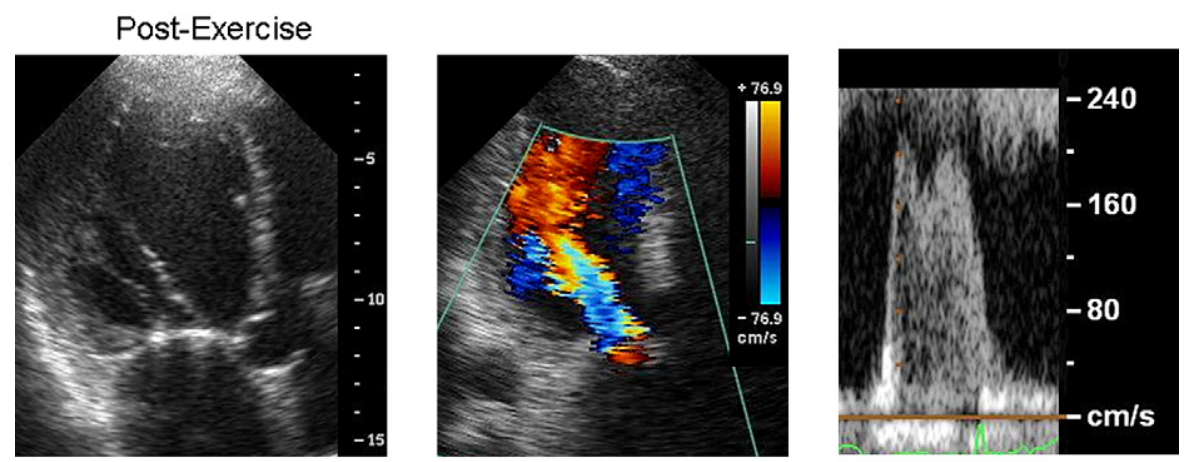

B

FIGURE 2. A, B, Dynamic worsening of functional MS observed by exercise stress echocardiography in a patient who underwent surgical annuloplasty for ischemic MR. During exercise, the left ventricle tended to dilate, mitral leaflet opening dimension decreased, and mitral flow velocity increased. 
a shortened diastolic filling time during exercise increase hemodynamic impairment, ${ }^{19}$ which is associated with a constant or increased MVA. However, MVA was also reduced during exertion in patients with functional MS in the present study, and this reduced MVA was significantly related to the reduced leaflet tip opening angle $\left(\mathrm{r}^{2}=0.26\right.$, $P<.01)$. Thus, the results suggest that increases in both heart rate and subvalvular tethering contribute to the exercise-induced hemodynamic impairment of functional MS.

\section{Relation to Previous Studies}

Decreased mitral leaflet opening in patients with LV dysfunction ${ }^{7}$ has been widely attributed to decreased transmitral flow volume. However, mitral leaflet opening is independent of inflow volume, ${ }^{8,9}$ and reduced leaflet opening in LV dysfunction reflects diastolic leaflet restriction caused by subvalvular tethering. ${ }^{9,10}$ The mitral inflow volume (LV EDV - LV ESV) and the MVA also did not significantly correlate in the present study. These findings confirmed that mitral leaflet opening is independent of inflow volume and that the postoperative reduction in MVA in the current study was not likely to be associated with reduced mitral inflow volume after the reduction in the MR by the procedure.

Surgical mitral annuloplasty with downsizing has been widely applied in the management of ischemic MR. ${ }^{20-22}$ The development of functional MS after such interventions has not been emphasized in the literature. However, previous evaluations of diastolic mitral valve opening after ring annuloplasty for ischemic $\mathrm{MR}^{20-22}$ have also found a mild but considerable increase in mean transmitral PG (2.5-3.1 $\mathrm{mm} \mathrm{Hg}$ ) compared with controls in both the present $(0.6$ $\pm 0.2 \mathrm{~mm} \mathrm{Hg})$ and another $(1.4 \pm 0.8 \mathrm{~mm} \mathrm{Hg})^{23}$ study. Magne and colleagues ${ }^{11}$ recently discovered a high incidence of functional MS after restrictive annuloplasty for ischemic MR and its influence on hemodynamic impairment and pulmonary hypertension. ${ }^{24}$ The results of the present study are consistent with these reports. The present study further demonstrated that subvalvular tethering from the $\mathrm{LV}$ remodeling is the primary mechanism of the functional MS at the leaflet tip level, which can explain why a surgical ring with area of more than $2.7 \mathrm{~cm}^{2}$ (Carpentier-Edwards Physio Ring 24 or greater) can cause functional MS with MVA less than $1.5 \mathrm{~cm}^{2}$; however, surgical annular ring reduction creates an important substrate for this tethering, because patients with tethering alone before annular ring implantation do not have such evident functional MS.

Magne and colleagues ${ }^{11}$ observed a significant improvement in functional MS (ie, an increase in MVA) after dobutamine infusion, which suggested that dobutamine could attenuate the LV dilatation and subvalvular tethering. They also observed a significant increase in MVA during exertion, which was in contrast with our findings that demonstrated decreased MVA during exercise. A possible explanation for these differences might be related to the different responses of the LV performance between the 2 studies. LV ejection fraction significantly improved $(43 \% \pm 14 \%$ to $58 \% \pm 10 \%, P<.01)$ in their study, but tended to deteriorate $(47 \% \pm 14 \%$ to $42 \% \pm 12 \%$, not significant $)$ in ours. Because the response of the MVA to exercise might be related to the $L V$ response, a reduced MVA during exercise without improved LV performance would be consistent with an increased MVA during exertion with improved LV performance. Therefore, the present results suggest that exertion can indeed cause functional MS to dynamically deteriorate or improve, depending on the $\mathrm{LV}$ response to exercise.

\section{Clinical Implications}

Functional MS may be expected to be caused solely by the small ring itself, and the solution is to simply use a larger ring. However, functional MS developed in this study without downsizing of the annular ring. The current findings indicate that the cause of functional MS involves LV remodeling with subvalvular tethering, which is also the mechanism of recurrent systolic ischemic MR. The practical consequence of this is that subvalvular tethering ${ }^{25}$ should be reduced to achieve not only a better repair for systolic MR but also better diastolic filling and exercise function. With respect to the ideal size of the surgical ring, whereas annuloplasty with an undersized ring is beneficial, ${ }^{20-22}$ the current study suggests that perhaps more caution is required when applying a more aggressive annular size reduction for ischemic MR.

\section{STUDY LIMITATIONS}

The number of patients in the current study was limited; therefore, the incidence, degree, and mechanism of functional MS after annuloplasty in different myocardial infarction locations was not evaluated. Although symptoms or measurements did not significantly differ between patients with a Carpentier-Edwards Physio ring or a linear reducer, an accurate comparison was not feasible without randomization. The degree of the functional MS in the present study seems to be milder than that reported by Magne and colleagues. ${ }^{11}$ One explanation might be that highly downsized rings were not applied in the current study. The number of patients who underwent the exercise study was also limited. Most of them were fully revascularized, and none developed chest pain or new wall motion abnormalities by echocardiography during exercise. Thus, the relationship between exercise-induced ischemia and functional MS was not investigated. The timing of echocardiographic study after the surgery varied, and the time lapse from surgery to the echocardiographic study and patient status did not significantly correlate. However, the chronologic course of patient status, including functional MS, requires further study. Three-dimensional evaluations are necessary to fully characterize the complex geometry of this functional MS. Other 
mechanisms, such as excessive leaflet tissue within the orifice, might be involved in functional MS.

\section{CONCLUSIONS}

Surgical annuloplasty for ischemic MR caused frequent and significant MS that was associated with restricted leaflet opening because of subvalvular diastolic tethering and a reduced annular size. This functional MS was related to heart failure symptoms and especially relevant during exercise with dynamic worsening, suggesting the need for procedures to address subvalvular tethering in these patients.

\section{References}

1. Godley RW, Wann LS, Rogers EW, Feigenbaum H, Weyman AE. Incomplete mitral leaflet closure in patients with papillary muscle dysfunction. Circulation. 1981;63:565-71.

2. Ogawa S, Hubbard FE, Mardelli TJ, Dreifus LS. Cross-sectional echocardiographic spectrum of papillary muscle dysfunction. Am Heart J. 1979;97:312-21.

3. Otsuji Y, Handschumacher MD, Schwammenthal E, Jiang L, Song JK, Guerrero JL, et al. Insights from three-dimensional echocardiography into the mechanism of functional mitral regurgitation: direct in vivo demonstration of altered leaflet tethering geometry. Circulation. 1997;96:1999-2008.

4. Yiu SF, Enriquez-Sarano M, Tribouilloy C, Seward JB, Tajik AJ. Determinants of the degree of functional mitral regurgitation in patients with systolic left ventricular dysfunction: a quantitative clinical study. Circulation. 2000;102:1400-6.

5. Komeda M, Glasson JR, Bolger AF, Daughter GT II, MacIsaac A, Oesterle SN, et al. Geometric determinants of ischemic mitral regurgitation. Circulation. 1997; 96(Suppl II):II128-33.

6. Agricola E, Oppizzi M, Maisano F, De Bonis M, Schinkel AF, Torracca L, et al. Echocardiographic classification of chronic ischemic mitral regurgitation caused by restricted motion according to tethering pattern. Eur J Echocardiogr. 2004;5: 326-34.

7. Rasmussen S, Corya BC, Feigenbaum H, Black MJ, Lovelace DE, Phillips JF, et al. Stroke volume calculated from the mitral valve echogram in patients with and without ventricular dyssynergy. Circulation. 1978;58:125-33.

8. Massie BM, Schiller NB, Ratshin RA, Parmley WW. Mitral-septal separation: new echocardiographic index of LV dysfunction. Am J Cardiol. 1977;39: 1008-16.

9. Otsuji Y, Gilon D, Jiang L, He S, Leavitt M, Roy MJ, et al. Restricted diastolic opening of the mitral leaflets in patients with left ventricular dysfunction: evidence for increased valve tethering. J Am Coll Cardiol. 1998;32:398-404.
10. Wisenbaugh T. Doing away with dogma: increasing afterload to reduce mitral regurgitation. J Am Coll Cardiol. 1999;33:538-45.

11. Magne J, Sénéchal M, Mathieu P, Dumesnil JG, Dagenais F, Pibarot P. Restrictive annuloplasty for ischemic mitral regurgitation may induce functional mitral stenosis. J Am Coll Cardiol. 2008;51:1692-701.

12. Lancellotti $P$, Troisfontaines $P$, Toussaint AC, Piérard LA. Prognostic importance of exercise-induced changes in mitral regurgitation in patients with chronic ischemic left ventricular dysfunction. Circulation. 2003;108:1713-7.

13. Piérard LA, Lancellotti $P$. The role of ischemic mitral regurgitation in the pathogenesis of acute pulmonary edema. N Engl J Med. 2004;351:1627-34.

14. Terai H, Tao K, Sakata R. Surgical treatment for ischemic mitral regurgitation: strategy for a tethered valve. Ann Thorac Cardiovasc Surg. 2005;11:288-92.

15. Ormiston JA, Shah PM, Tei C, Wong M. Size and motion of the mitral valve annulus in man. I. A two-dimensional echocardiographic method and findings in normal subjects. Circulation. 1981;64:113-20.

16. Hung J, Papakostas L, Tahta SA, Hardy BG, Bollen BA, Duran CM, et al. Mechanism of recurrent ischemic mitral regurgitation after annuloplasty: continued LV remodeling as a moving target. Circulation. 2004;110(11 Suppl 1):II85-90.

17. Gilon D, Cape EG, Handschumacher MD, Jiang L, Sears C, Solheim J, et al. Insights from three-dimensional echocardiographic laser stereolithography: effect of leaflet funnel geometry on the coefficient of orifice contraction, pressure loss, and the Gorlin formula in mitral stenosis. Circulation. 1996;94:452-9.

18. McGee EC, Gillinov AM, Blackstone EH, Rajeswaran J, Cohen G, Najam F, et al Recurrent mitral regurgitation after annuloplasty for functional ischemic mitral regurgitation. J Thorac Cardiovasc Surg. 2004;128:916-24.

19. Voelker W, Jacksch R, Dittmann H, Schmidt A, Mauser M, Karsch KR. Validation of continuous-wave Doppler measurements of mitral valve gradients during exercise: a simultaneous Doppler-catheter study. Eur Heart J. 1989;10:737-46.

20. Bax JJ, Braun J, Somer ST, Klautz R, Holman ER, Versteegh MI, et al. Restrictive annuloplasty and coronary revascularization in ischemic mitral regurgitation results in reverse left ventricular remodeling. Circulation. 2004;110(Suppl II): II103-8.

21. Bolling SF, Pagani FD, Deeb GM, Bach DS. Intermediate-term outcome of mitral reconstruction in cardiomyopathy. J Thorac Cardiovasc Surg. 1998;115:381-6.

22. Bolling SF, Deeb GM, Brunsting LA, Bach DS. Early outcome of mitral valve reconstruction in patients with end-stage cardiomyopathy. $J$ Thorac Cardiovasc Surg. 1995;109:676-82.

23. Jawad IA, Ghali MH, Brown RL, Sohn YH. Pressure-flow relations across the normal mitral valve. Am J Cardiol. 1987;59:915-8.

24. Marwick TH. Restrictive annuloplasty for ischemic mitral regurgitation: too little or too much? J Am Coll Cardiol. 2008;51:1702-3.

25. Di Donato M, Castelvecchio S, Brankovic J, Santambrogio C, Montericcio V, Menicanti L. Effectiveness of surgical ventricular restoration in patients with dilated ischemic cardiomyopathy and unrepaired mild mitral regurgitation. J Thorac Cardiovasc Surg. 2007;134:1548-53. 